\title{
Why Asynchronous Computer-Mediated Communication (ACMC) Is a Powerful Tool for Language Learning
}

\author{
Mark Brooke \\ Department of Linguistics and Modern Languages, Hong Kong Institute of Education, Hong Kong, China \\ Email: mbrooke@ied.edu.hk
}

Received June $8^{\text {th }}$, 2012; revised August 22 ${ }^{\text {nd }}$, 2012; accepted August 30 ${ }^{\text {th }}, 2012$

\begin{abstract}
Tertiary institutions are increasingly using online virtual environments such as Blackboard to upload course content for students. However, there is still limited usage of the online blogging and discussion tools. This study describes the language used by tertiary students involved in blogging and discussions online. It also demonstrates learning processes observed through the interactions of participants over time. Findings suggest that this unique discourse mode is a potentially powerful tool for language learning.
\end{abstract}

Keywords: Asynchronous Computer-Mediated Communication (ACMC); Second Language Acquisition (SLA); Mutually-Constructed Meanings; Incidental Learning; Linguistic Diversity

\section{Introduction}

Gustafson, Hodgson and Tickner (2004: p. 5) state:

"We would like to stress the importance of discourse analysis as a tool/method for looking closer at dialogue patterns when researching networked learning environments and trying to explain the possible failures or successes of such environments.”

By successes, the authors refer to the kind of learning that takes place in an online asynchronous environment. This research has analysed the discourse from thirty online forums, consisting of around one-hundred and fifty postings (ranging from fifty to three hundred words in length), to present the English language used by groups of advanced learners of English as a second language and to link this language with processes of learning identified online. It is hoped that this study describes why the online asynchronous learning environment is an effective one for learning English as an additional language.

The first part of this article "SLA theories of language learning and the potential of ACMC" examines language learning theory based on Second Language Acquisition (SLA).

This provides the conceptual basis of the study.

The second part "processes of learning" uses empirical evidence to demonstrate 2 types of social learning identified. These are mutually-constructing meanings and incidental learning.

The third part of this article "ACMC language product" is a description of the linguistic diversity identified in this researcher's second language learning context. This section reveals that the ACMC is a uniquely rich language environment where differing text formats appear and spoken and written discourse as well as differing tenors can cohabite easily, even to the extent of coinciding within clauses.

\section{Conceptual Basis of the Study: SLA Theories of Language Learning and the Potential of the ACMC}

\section{Social and Deeper Learning}

It is commonly known that Vygotskian $(1962,1978)$ premises focus primarily on the social construct of the human consciousness. Cognitive language growth is embedded in the dynamics of social interaction. Consequently, learners are rarely isolated, encapsulated knowers or doers and benefit more in the field of second language learning through social intercourse to enable them to use the language they learn in context. In addition, and according to constructivist thinking, groups can construct meanings together through negotiation and reach higher levels of consciousness leading to deeper learning than isolated individuals. A significant element to these notions is that the need for language retrieval for communicative purposes facilitates the learning of that language. This is inextricably linked with the notions of “Communicative Language Teaching' (see Howatt, 1984: 279). Another key element is that social learning enables the language learner to learn pragmatic uses of language or communicative functions such as agreement or persuasion, evaluation or argumentation. It was Wilkins (1976) who first published on this aspect of meaning-based syllabi coining the term of "notional syllabuses".

\section{Noticing Language}

Van Lier (1996: p. 11) states:

“To learn something new one must first notice it. This no- 
ticing is an awareness of its existence, obtained and enhanced by paying attention to it. Paying attention is focusing one's consciousness, or pointing one's perceptual powers in the right direction, and making mental 'energy' available for processing".

This "noticing" followed by a more focused "paying attention" encapsulates what Schmidt (1994) points out as two of the main functions of the intra-mental consciousness (in contrast to the inter-mental) in Vygotskian terminology: attention (noticeing and focusing on information) and intention (learning something intentionally rather than unintentionally while doing something else). In other words, learners will normally only learn a linguistic item when they are ready to do so, when their mental lexicon is able to absorb it.

For second language educators, it is thus quintessential to seek to facilitate these processes by offering a communicative environment for their students which is language-rich. In other words, second language learners should be exposed to a variety of text types in both written and spoken mode, offering a wide range of language along the discourse mode and tenor continuum (Halliday, 1975, 2004). As Hatch (1996: p. 209) posits coherence in talk and writing is attained via overall system constraints on communication, by calling up generic scripts that fit the communication situation, by knowing the structure of speech events, and by recognizing the ways information may be formatted in various rhetorical genres.

\section{Risk-Taking}

Krashen (1982) refers to affective barriers to second language acquisition. These are commonly understood as the areas involving feelings, emotions, mood and temperament. It is believed that these elements are greatly reduced in the ACMWC environment (Lewis and Allan, 2005: p. 45). This is in part due to the fact that access can be closed but is particularly due to the discourse mode of asynchronous written communication (ACMWC). With asynchronicity, students have time to reflect upon and formulate their thoughts before expressing them and engaging in interaction. In contrast to spontaneous and timebound synchronous interaction, studies have revealed that this genre of communication enables students to produce a greater quantity and better quality of discourse than in an oral classroom (Ortega, 1997; Peters, 2000). They also lead to more equal participation between students (Warschauer, 1996) and ultimately deeper learning. In this way, it is suggested that students might be more absorbed in the tasks and less concerned with linguistic errors or deviances from the norm.

\section{The Study}

\section{Material and Methods}

The research objective was to:

- Analyze how an online environment's e-journaling (blogging) tool and forum tool might enhance groups of $3^{\text {rd }}$ year Chinese BEd pre-service teachers' English as a second language learning capabilities.

To meet this objective, the following questions were asked:

- What processes of language learning can be observed online? What language structures (genre types, language structures, and interactional patterns) emerge through language use online between participants?

\section{Context}

The research was conducted as part of the pre-service teacher education field experience practicum at the Hong Kong Institute of Education. Students are mother tongue Cantonese speakers who are training to be English language teachers in primary and secondary state schools. Students are placed in local state schools for 6 weeks during their $3^{\text {rd }}$ year practicum. They are expected to manage and deliver English as a additional language courses to their students. The online asynchronous forums were set up primarily as a support line for these student teachers during practicum. By using the blogging and discussion forums, trainees could receive support from this researcher who was their mentor as well as support from each other by sharing their experiences online. Thus, the language production and learning that took place was observed as it emerged through communication. At no stage were participants informed that the site had been set up for language learning. In addition, the language analyses performed and described in this article were conducted at the end of the case studies. Thus, this researcher did not intentionally promote the language use described online. Rather, the data were observed through postcase study analysis. Further, participants were instructed to use the sites independently, without aid from native or near-native language users. Participants were fully aware that the use of the sites was not part of an assessment cycle rendering it a platform for natural, fluent language not requiring thoroughly proof-read postings.

\section{Participants}

Three case studies of eight weeks were conducted. Each case study consisted of eight third-year participants of a four-year BEd (EL) degree from both Hong Kong and mainland China aged between 20 and 25. There was a mix of male and female students aged between 20 and 25. Pseudonyms of participants are used.

\section{Design}

The research was performed by this researcher in his capacity as teacher educator-researcher using action research methodology. Action research as Lewin (1946: p. 206) posits, involves:

"A spiral of steps, each of which is composed of a circle of planning, action, and fact-finding about the result of the action”.

Through experimentation and multiple observation of empirical evidence, data were collated in research observational note forms. Thus findings were constructed and continually refined over time. The virtual learning environment used was Blackboard and participants had closed access to the sites, offering some privacy as only those registered could write about their experiences and read those of their peers. This was believed to be a low risk environment to facilitate trainee critical and creative thinking as well as cooperative and collaborative learning. This prediction was substantiated at the end of each case study as participant interviewees reported that they were happy to share their views online.

\section{Procedure}

\section{Phase 1}

A welcoming announcement was sent out to participants 
telling them that the site would be available for support and inviting them to introduce themselves online and to share any views about the practicum experience to follow. Participants were at no stage told that their language for blogging or discussion would be analyzed.

\section{Phase 2}

After the first week of teaching, participants began posting their weekly blogs.

\section{Phase 3}

Each week a new forum was added to the sites and this was used for weekly reports and discussions. This researcher acted as online moderator inviting participation and facilitating interaction if required.

\section{Phase 4}

At the end of each case study, threads were collected for textual analysis and research findings written up and evaluated.

\section{Results}

In this section, the processes of language learning observed are presented. These processes relate to the SLA characteristics noted above e.g., social and deeper learning, noticing, and risk taking.

\section{Processes of Learning}

\section{Mutually Constructing Meanings}

Student A: "I wonder whether it is necessary for teachers to write lesson plans for EVERY SINGLE lesson. I know that it is helpful to spend time preparing learning materials for students and to plan beforehand the objectives and structure of lessons. Yet, is it a must to put down detailed steps and the time each step takes in a lesson plan"?

Student B: "I don't think for teachers who are already overwhelmed with their overloading work, writing lesson plans for every single lesson is not necessary. However, it is important for us-student teachers-to write enough lesson plans, so that we can learn to carefully plan what to do in a lesson, see whether it works out and reflect on how to improve it for the next time. I guess this is just a process every teacher has to go through. Once we feel that we don't need to write it anymore, we don't have to write it. But I guess it would still be good for experienced teacher to write some lesson plans from time to time for lesson improvements".

Student C: "I agree with Tian that we, student teachers, should write lesson plans in the preliminary stage of our teaching. Every time we revise our lesson plans based on our accumulated experience, we are making progress".

In this excerpt of interaction, it is possible to see the language construction process. The first student commences the topic of discussion. Then student B replies. Student B's response is in non-academic language. In contrast, student $\mathrm{C}$ encapsulates what B discusses by defining B's meanings: "preliminary stage" is used for "student teachers"; "revise" is used for "reflecting on how to improve it"; and "accumulated experience" is used for "a process every teacher has to go through". All of these terms used by student $\mathrm{C}$ are improving the conceptual and academic content of B's responses by summarizing them or remodelling them to improve them. This makes the dialogue a construction zone. This is therefore a good example of how participants can learn from each other online for second language acquisition to occur. The language used by B was non-academic. In contrast, C's language was academic and B's noticing of these language items has been facilitated through communication. This is further discussed below as part of "incidental learning". In a way, this is a form of scaffolding language as $C$ is helping to raise B's awareness of more complex ways of communicating the same ideas. This therefore reveals C's awareness of B's zone of proximal development. $\mathrm{C}$ is guiding $\mathrm{B}$ to use more complex language. Other examples of refining language or retuning it to teach it were continuously remarked during the case studies.

\section{Incidental Learning}

The following originates from a discussion on teaching reading in the secondary school classroom. The online interaction takes place over a period of 2 days.

Day 1

Trainee 1 states: "I got a big problem-students found the reading I gave them too difficult. I looked up the words on odd number pages for them and I went through the 1st paragraph with them together in class too but they still found it too difficult."

What follows then is a discussion between her and her trainer during which the trainer states:

Trainer: "You can pre-teach any crucial vocabulary initially and inform them that it's not necessary to comprehend every single word to enjoy the story. If the language is problematic, the text might be too difficult but there's no harm in trying the book out-why don't you should select 2 or 3 short extracts for students to read over the holiday and then go through those as a shared reading when you're back"?

Day 2

A previously vicarious participant adds to the dialogue:

Trainee 2: "I told students they didn't need to know all the words. I don't think they had thought about it before. Then I gave them the essential vocabulary and I read students a page of a graded reader of Birthday Girl" by Haruki Murakami. They said they liked it even though it was difficult. So it can help to tell them they don't need to know everything :-)".

Trainee 1 replies on the same day: "I could try a graded reader if the level is too difficult."

This is then rounded off by trainee 2, also on day 2, who states: “Good idea! Didn't think of telling you about graded readers"!

Trainee 1 has been guided to try out a new idea for reading instruction through her peer's postings. However, as the peer admits, the mention of a graded reader was not meant to be a learning point. In other words, in an online environment such as this, unplanned learning can occur. This particular example of learning is not at the word level but rather at the ideational level. As long as classroom practice is discussed between stakeholders, learning of this kind seems to be facilitated on a regular basis because issues are discussed which each member can relate to.

Incidental learning at the word or word group level did occur also. In the excerpt above, the term accumulated experience was used by B in a later posting. This was then followed up by this researcher at the end of the case study. Participant B was asked if she was aware of the term prior to the study. She stated 
that she had not been and was not aware that she had used it either. When asked about her prior knowledge of collocations that co-exist with "experience" in this way, the participant answered that she might have used "growing" or "previous" but would not have used "accumulated". The fact that she did use the term "accumulated experience" in a later posting suggests therefore that this was an example of noticing language and, the fact that she was not aware that she had used it, suggests that she had learned it incidentally.

\section{Language Variety Observed in the CMC Environment}

In the following section, the author will provide a description of the language generated online by participants. If the processes of learning in Section 1 of the results occur frequently, the language used during communication is very important because it is part of the language that learners are learning through their interactions. The first observation presents the text structures used for communication. The tenor for these structures can be both informal and formal.

\section{The Text Types Used for the Organization of the Discourse}

This first data presentation will focus on the kinds of texts used for communication over the 3 case studies as well as the formulaic expressions that pertain to these text types.

The CMC is most often formatted in letter form or report form. However, within these forms, it also contains narrative, personal recount or procedural texts. In addition, there is frequently a much more interactive conversational style of discourse with much shorter turns taken, use of smileys and other examples of phatic communion.

- $\quad$ The letter format

Some users prefer to use informal letter writing styles. Others prefer more formal letter writing style. The following are salutations and closings observed:

Informal salutations: Hi everyone; Howdy; Hello everyone; Hiya all; Hi there.

Formal salutations: Dear + name; Dear + fellow classmates; Dear + fellow course mates; Dear all/Dear everyone

Informal closings: Best wishes; Best; Thank you; Isn't it interesting? Haha!; Hope it helps :-; Talk to all of you later!; Will keep you updated on this; Can't think of anything more at the moment-I will keep you updated asap; How are you all going? $M$; Interested to know what others in the group think?; Want to know what happens next? It's coming soon!; Tbc wk 3; Gd Rdgs.

Formal closings: I am looking forward to your suggestions and sharing; I'm looking forward to hearing from you; I hope these ideas are useful and I look forward to hearing other people's ideas.

- The report format

A posting may also take a report format with a title such as "Struggling with teaching". This might then be followed by sub-headings e.g., Classroom observations; Teaching grammar etc. In this case, no salutation or closing is used as with the letter format.

\section{The Writing Genres Used for Blog Postings}

The letter or report format might be used as the structure of the text but the actual language used is most commonly based on genre types such as personal recounts/narrative descriptions or expository texts analyzing an issue of significance or an argumentative explaining and justifying someone's view on something.

- The narrative genre

As with narrative constructions, there tends to be an "orientation": "I still find some problems with my class that I am worried about"; a problem: "my supporting teacher suggested to me that I should teach activity sheets in class as they do". They are repetitive drilling exercise $*$ I am afraid that abandoning those activity sheets will offend my supporting teacher", a solution: I will try to negotiate with my supporting teacher later about this issue, and a Coda: "those are my reflections. I would like to hear your advice."

- The expository genre

As with expository texts, there tends to be topic priming: $I$ have several concerns about teaching in a co-teaching mode, followed by a sequencing of points expanding on the priming: First of all, with co-teaching, every lesson must be taught by 2 people. Secondly, in terms of the organization of a lesson, whilst one person is lecturing, the other must play a role as the TA. Thirdly, the actual individual teaching time we have is less.

\section{A Mixture of Conversational English and Written English}

There appears to be a range of both spoken and written discourse features that can be used at any time in long or short utterances. No rules tend to apply.

- Written discourse grammar

However I've got a lot of problems Nevertheless I will work harder cheers! ^^^

The teacher understanding the students' needs has been adopting a rather exam-oriented mode of teaching which provides students with loads of assignments.

- Spoken discourse grammar

These can occur within a clause, a kind of code mixing: "We need to strike a balance between drilling and meaningful tasks. Ya the pretty blur term balance again."

Or from one clause to the next in a kind of code switching: "A prerequisite to becoming a teacher is to appreciate literature and music. The Phantom of the Opera is awesome."

\section{The Interactional Communicative Functions}

As is common with spoken discourse, the following meaning-based functions have been observed on a regular basis:

- Statement of opinion: "what bothers me is that this school is quite different from the school I went to last year. Frankly, we prepared more precisely for the observations".

- Giving advice: "additionally, you may try to stick some strips of question types and its Chinese meaning onto the wall to facilitate students" understanding to your questions."

- Self evaluation: "actually I didn't prepare very well last week and I was disappointed in my performance".

- Evaluating others: "regarding setting two versions of handouts for students, I am not sure if this is the most suitable way to do it”.

- Asking questions: "is it OK to use Chinese in English teaching too facilitate lower level students?”

- Asking for advice: should I follow the traditional routine of teaching?

- Answering questions: "My supporting teacher told me that she sometimes uses Chinese to support those less confident students". 
- Hypothesizing: "If I had to use English only in class, it would be difficult for me to make them understand my instructions."

- Agreeing and disagreeing: "You are so right to say that everything is so relative/I am not sure if the reality can be so ideal. Nevertheless, I would incline to Crystal's suggestion".

- Expressing gratitude: "Thanks for the encouraging message!”

- Expressing regret: "We wish that they would enjoy the lessons.”

- Reporting others' advice or opinions (both spoken and written forms with recursive tense and without): "one teacher told me that the students I am going to teach are quite 'ACTIVE'. She told me that the students said I had taught too fast."

- Referring to others' points: "I totally understand your feelings when getting the wrong response from students."

- Rhetorical statements or questions: "I think most of you have already heard of this activity”.

\section{Discussion}

The results demonstrate how second language learners involved in ACMC construct meanings together or learn from each other when engaged in discussion online. They also reveal that online written communication might have the same potential for developing linguistic competence through negotiation of meaning as oral interaction does. Both noticing and incidental learning occur frequently and construction of meaning can be traced through the postings. In addition, the results demonstrate that the asynchronous written discourse environment is one which facilitates a range of written text formats, linguistic features specific to narrative and expository genres and communicative functions encompassing a great variety of interactional meaning-based expressions more common to spoken communication. The environment often presents language as a hybrid of spoken/written modes both within clauses, between clauses as well as in the form of greater chunks of spoken or written discourse at text level. These occurrences tended to depend on the type of interaction being used prior to a posting or on the psychological state of the participant and his/her relationship to the event/ topic of discussion i.e., if the topic was deemed to be a very serious one, it was more likely to be described in report format using more formal tenor; if it was a more jovial posting, it tended to be in letter format with more elements of spoken discourse features.

\section{Conclusion}

It is this author's opinion that the language learning processes and language varieties described from this study, reveal that this environment is an extremely powerful one for second language learning; in this author's context, for the learning of the English language. In addition, as a relatively new form of communication, it is evolving and creating its own characteristics. These characteristics tend to be what might be called "tenor-inclusive", encouraging discourse representing language along the continuum of formality. They also tend to combine both spoken and written discourse features at clause, sentence and text levels. Future research using more longitudinal studies with larger groups interacting together might reveal the evolu- tion of new emerging discourse modes. These studies might also help to validate this research if the same instances of learning and language are observed.

\section{REFERENCES}

Chandler, P., \& Sweller, J. (1991). Cognitive load theory and the format of instruction. Cognition and Instruction, 8, 293-332. doi:10.1207/s1532690xci0804_2

Chun, D. (1994). Using computer networking to facilitate the acquisition of interactive competence. System, 22, 17-31. doi:10.1016/0346-251X(94)90037-X

Gustafson, J., Hodgson, V., \& Tickner, S. (2004). Identity construction and dialogue genres-How notions of dialogue may influence social presence in networked learning environments. Proceedings of the Fourth International Conference on Networked Learning, Lancaster, 5-7 April 2004.

Halliday, M. A. K. (1975). Learning to mean-Explorations in the development of language. London: Edward Arnold.

Halliday, M. A. K. (2004). An introduction to functional grammar (3rd ed.). London: Education and Lifelong Learning.

Hatch, E. (1992). Discourse and language education. New York: Cambridge University Press.

Howatt, A. (1984). A history of English language teaching. Oxford: OUP.

Kember, D. (1996). The intention to both memorise and understand: Another approach to learning. Higher Education, 31, 341-354. doi:10.1007/BF00128436

Kern, R. (1995). Restructuring classroom interaction with networked computers: Effects on quantity and quality of language production. Modern Language Journal, 79, 457-476. doi:10.1111/j.1540-4781.1995.tb05445.x

Krashen, S. (1982). Principles and practice in second language acquisition. London: Pergamon Press Inc.

Lewin, K. (1946). Action research and minority problems. Journal of Social Issues, 2, 34-46. doi:10.1111/j.1540-4560.1946.tb02295.x

Lewis, D., \& Allan, B. (2005). Virtual learning communities: A guide to practitioners. Berkshire: McGraw Hill.

Marton, F., \& Saljo, R. (1976). On qualitative differences in learning II: Outcome as a function of the learner's conception of the task. British Journal of Educational Psychology, 46, 115-127. doi:10.1111/j.2044-8279.1976.tb02304.x

Ortega, L. (1997). Processes and outcomes in networked classroom interaction: Defining the research agenda for L2 computer-assisted classroom discussion. Language Learning \& Technology, 1, 82-93.

Pellettieri, J. (2000). Negotiation in cyberspace: The role of chatting in the development of grammatical competence. In M. Warschauer, \& R. Kern (Eds.), Network-based language teaching: Concepts and practice. Cambridge: Cambridge University Press.

Peters, K. (2000). Concrete steps for on-line discussion. URL (last checked 19 September 2000).

http://booboo.webct.com/otln/Asynchronous_Strategies.htm

Prawat, R. S. (1996). Constructivisms: Modern and postmodern. Educational Psychologist, 31, 215-225.

Schmidt, R. W. (1994). Deconstructing consciousness: In search of useful definitions for Applied Linguistics. AILA Review, 11, 11-26.

Stevick, E. W. (1976). Memory, meaning and method. New York: Newbury House Publishers.

Van Lier, L. (1996). Interaction in the language curriculum: Awareness, autonomy, and authenticity. London: Longman.

Vygotsky, L. S. (1962). Thought and language. Cambridge, MA: MIT Press.

Vygotsky, L. S. (1978). Mind in society. Cambridge, MA: Harvard University Press.

Warschauer, M. (1996). Computer-assisted language learning: An introduction. In S. Fotos (Ed.), Multimedia language teaching. Tokyo: Logos International.

Wilkins, D. (1976). Notional syllabuses. Oxford: Oxford University Press. doi:10.1037/11193-000 